\title{
Princípios transdisciplinares do programa geração da paz: pontos de partida para extensão, pesquisa e formação
}

\author{
Rosamaria de Medeiros Arnt * \\ Paula Pereira Scherre ${ }^{\star *}$
}

\begin{abstract}
Resumo
Neste trabalho apresentamos as reflexões e sistematizações sobre princípios do Programa Geração da Paz, da pró-reitoria de extensão da Universidade Estadual do Ceará/Brasil, em realização desde 2010, que visa a formação de educadores para a Cidadania e para a Paz. Entendemos princípios como pontos de partida, que se relacionam de forma dinâmica, aberta e processual, permitindo o surgimento de arranjos inovadores, por considerarem a complexidade e a multirreferencialidade da realidade e a multidimensionalidade humana. Identificamos como princípios transdisciplinares: abertura, escuta, diálogo, flexibilidade, partilha e auto-organização. Conceituando-os, apresentamos como foram vivenciados na coordenação e nas formações e como repercutem nas práticas profissionais dos educadores participantes.
\end{abstract}

Palavras-chave: transdisciplinaridade, formação de educadores, educação para a paz.

Transdisciplinary principles of the program peace generation: starting points for extension, research and formation

\begin{abstract}
We present reflections and systematization of principles of the Program Peace Generation, of the pro-rector of extension of the State University of Ceará/Brazil, that have been taking place since 2010 and aims at forming educators for citizenship and peace. We understand principles as starting points, which relate between themselves with dynamic, open and procedurally, allowing the emergence of innovative arrangements, by considering the complexity and the multiple references of reality and human multidimensionality. We identify as transdisciplinarity principles: openness, listenin, dialogue, flexibility, sharing and self organization. Conceptualizing them, we show how they were experienced in coordinating and in forming and as echoed in the professional practices of participating educators.

Key words: transdisciplinarity, teacher formation, education for peace.

\footnotetext{
Professora da Universidade Estadual do Ceará/Grupo de pesquisa ECOTRANSD - Ecologia dos saberes, Transdisciplinaridade e Educação. E-mail: rmarnt@gmail.com. pscherre@ gmail.com.
}

** Grupo de pesquisa ECOTRANSD - Ecologia dos saberes, Transdisciplinaridade e Educação. E-mail:
\end{abstract}




\section{Introdução}

Neste artigo, apresentamos as reflexões e sistematizações do Programa Geração da Paz, da pró-reitoria de Extensão da Universidade Estadual do Ceará/Brasil. Este programa tem, em sua base, a pesquisa e a formação de educadores para a cidadania e para a paz, que atuem em meios comunitários ou em escolas públicas do estado do Ceará/Brasil. Abordamos princípios de concepção e formação adotados neste programa, na tentativa de investigar competências, conhecimentos e habilidades para o educador não somente do futuro, mas do presente, tendo em vista a sociedade que sonhamos: pautada na ética, no respeito à vida, na construção e manutenção da paz. Uma sociedade que se perceba cidadã e solidária, de acordo com a cidadania planetária definida por Edgar Morin (2000a).

Desde seu início, em 2010, o Programa Geração da Paz vem construindo sua identidade, encontrando um jeito próprio de se constituir, criar e se recriar a cada projeto desenvolvido. Vamos nos conscientizando de nossa maneira de conceber a Educação para a Paz e a vivência dos Direitos Humanos e de selecionar os temas geradores de nossas ações. Vamos desenhando nosso método de interagir com os parceiros, de compor e propor nossas práticas educativas, de manter permanentemente um processo formativo e investigativo que nos torne aprendentes, produtores e produtos de nossas ações. Vamos refletindo e experienciando, buscando ampliar nossa compreensão a cada contato, a cada diálogo, a cada leitura e releitura de textos, de autores e da realidade. Vamos nos descobrindo sempre capazes de perplexidade com as trocas e partilhas que cada encontro humano proporciona.

Por isso, antes mesmo de descrevermos nossas ações, reconhecemos nossos princípios e os diálogos que vimos estabelecendo com autores. Sim, mais do que 'fundamentos teóricos', temos, ao longo dos anos, em nossos estudos e leituras, dialogado de diferentes maneiras com Edgar Morin, Maria Cândida Moraes, Paulo Freire, Basarab Nicolescu, Ubiratan D’Ambrosio, Xesus Jares, entre outros.

Tomamos a transdisciplinaridade como referência maior de nossas ações, reconhecendo a existência de diferentes níveis de realidade, regidos por lógicas diferentes. Entendemos que a realidade, para ser conhecida, precisa da articulação da ciência, filosofia, artes e tradições, do que abrange as disciplinas, do que as atravessa e do que as ultrapassa. Entendemos que o conhecimento possui um desdobramento do ser para si, para o outro, para a realidade/totalidade, de forma integrada, integradora e transcendente. Não há como separar processos que, de forma complexa, se apresentam como um tecido, como um todo em constante construção. Observamos a importância das 
ações educativas considerarem a multidimensionalidade humana e a multirreferencialidade da realidade e buscamos, como meta dos processos formativos, a ampliação da consciência humana, por meio da compreensão objetiva e subjetiva (MORIN, 2000a), aliada à ética e à cidadania planetária.

\section{Sobre princípios e atitudes do Programa Geração da Paz}

Ao longo dos anos, com as parcerias e ações, fomos desenvolvendo nosso método de atuação, de construção conjunta de propostas, de formação de educadores. Fomos compreendendo nosso jeito de chegar, conversar, organizar e reorganizar propostas. Fomos identificando e entendendo os princípios que adotamos como base de nossas ações.

Princípios, para nós, são pontos de partida sobre os quais pensamos conjuntamente qualquer ação de extensão e pesquisa ligada ao Programa Geração da Paz. É preciso enfatizar que não fazemos concessão a princípios rígidos, que possam cristalizar-se e cristalizar-nos. Ao contrário, tentamos fugir da paralisação dada por 'pacotes prontos' que nos impeçam de visualizar outras possibilidades de entendimento da vida, da educação e de ações para geração da paz. Pensamos em princípios que se relacionem de forma dinâmica, aberta e processual, caracterizados pelo movimento e pelo fluxo, permitindo e acreditando na existência e pertinência de novos arranjos, incorporando ideias que se agreguem e complementem o que já foi vivenciado (ARNT, 2007). A partir dos princípios, a cada nova parceria formada, os pontos de chegada serão sempre outros, negociados pelos componentes do sistema humano em construção, sistema esse que terá características próprias, que deverão ser compreendidas à medida que os indivíduos e instituições interajam. Num tempo em que princípios, antes considerados universais, deixam de sê-lo, levamos em conta a transitoriedade do conhecimento, seu inacabamento, mas também a necessidade de ter uma base inicial de trabalho, de pensamento, de ação, mesmo que móvel, mutante.

Com estas referências, adotamos por princípios para nossas ações de extensão, educação e pesquisa no Programa Geração da Paz: abertura, escuta, diálogo, flexibilidade, partilha e auto-organização. Vamos descrevê-los, pois acreditamos - e a experiência ratificou - que eles são válidos não somente para projetos acadêmicos, mas para qualquer prática educativa, podendo se transformar em referência para os fazeres (e saberes) docentes. 


\subsection{Abertura}

A transdisciplinaridade se apresenta como uma atitude do ser perante o conhecimento e a realidade. Na Carta da Transdisciplinaridade, documento escrito em 1991, no Primeiro Congresso Mundial de Transdisciplinaridade, encontramos no artigo 14 a abertura, o rigor e a tolerância como características da atitude transdisciplinar. Compreendendo que cada novo projeto possui em si o inesperado, a emergência, o desconhecido, o primeiro princípio das ações do programa Geração da Paz é a abertura. Abertura à nova configuração, baseada no que já implementamos, pelo acolhimento de novos parceiros. Abertura necessária para a compreensão da realidade e dos cenários locais que encontramos e não conhecemos. Abertura ao novo, ao que precisamos apreender para que uma ação proposta possa ser ressignificada no contexto que adentramos. Abertura ao emergente, ao inusitado que somente poderá surgir nesta postura.

Paulo Freire (1997, p. 151) nos recomenda a atitude aberta aos dados da realidade e ao outro que compõem conosco um sistema a ser criado. Recomenda-nos "a desconfiança metódica que nos defende de nos tornarmos absolutamente certo das certezas". Para este educador, o pensar certo nos faz ser expostos “às diferenças, recusar posições dogmáticas, em que me [nos] admita como proprietário da verdade" (FREIRE, 1997, p. 151).

Assim, ao iniciarmos um novo projeto, levamos conosco a aprendizagem que os projetos já vividos nos proporcionaram e a inspiração que representam para cocriarmos outros tantos. Considerando a multirreferencialidade da realidade, o sentido profundo do inacabamento humano, consequentemente, de qualquer ação humana, cada novo ato começa com a apresentação de nossas experiências, mantendo-nos disponíveis a tocar e sermos tocados. E continua, pelo princípio da abertura, com a escuta dos parceiros, para a construção coletiva de um novo projeto.

\subsection{Escuta}

A escuta, como princípio, é para nós caracterizada como atenta e sensível. Consideramos que esta é uma importante maneira de compreendermos a realidade que nos cerca, nova e inovadora, inesperada e dificilmente concebida, mesmo que já tenhamos lido ou participado de alguma outra ação semelhante. Ouvir sobre o cenário que se abre a partir das pessoas nele envolvidas é, acreditamos, fundamental para a composição de qualquer proposta. 
Entendemos a escuta sensível, de acordo com René Barbier (2002, p. 94), como um:

'escutar/ver' (...) que pende para o lado da atitude meditativa no sentido oriental do termo. A escuta sensível apoia-se na empatia, (...) reconhece a aceitação incondicional do outro. Ela não julga, não mede, não compara. Ela compreende sem, entretanto, aderir às opiniões ou se identificar com o outro, com o que é enunciado ou praticado.

A escuta sensível pressupõe uma 'escuta atenta', ou seja, um estado de presença que permita "ouvir mais devagar, para perceber também os sons da vida que nos cerca. Escutar com atenção e mais devagar para ouvir o inaudível, para que nos acostumemos a sentir e pensar os detalhes sutis da fala do outro" (ARNT, 2007, p. 121).

A escuta atenta e sensível é o meio pelo qual podemos sair de nosso ponto de vista, sempre parcial, incompleto, fragmentado e fragmentador, reducionista e redutor. É o meio de compreendermos onde estamos, articulando o contexto, o global, o multidimensional e o complexo. Para Morin (2000a), o contexto é dado quando situamos as informações e os dados ao local de onde emergem, aos seus agentes e autores. O global, mais que o contexto, é o conjunto das partes que se ligam a ele, de modo inter-retroativo ou organizacional. É o conjunto que se recompõe a partir do conhecimento das partes, identificando as qualidades ou propriedades que somente surgem no todo que formam. O multidimensional nos faz pensar que o ser humano, como a sociedade, é simultaneamente biológico, psíquico, afetivo, racional, com dimensões históricas, econômicas, políticas, religiosas, sociais, entre outras. Compreender o meio em sua complexidade significa unir o contexto, o global, o multidimensional, considerando-os como elementos diferentes e inseparáveis.

Abrir-se à escuta nos parece imprescindível à estruturação de qualquer proposta que pretenda mergulhar na realidade que nos acolhe, no cuidado e no respeito de reconhecer que nunca teremos uma proposição melhor do que a construída pela união das partes que representam os parceiros na ação.

A escuta requer tempo. Muitas vezes, em nome das urgências e emergências, em nome da eficácia(!) nos asfixiamos na padronização, na repetição de fórmulas, na domesticação que Paulo Freire (1997) chama de 'burocratização da mente', que nos faz acomodados, recuando frente à necessidade de escolhermos juntos, decidirmos juntos, compromissarmo-nos juntos com o modo de pensarmos/agirmos e propormos mudanças à realidade. 
$\mathrm{Na}$ abertura e na escuta, criamos o campo propício ao diálogo e às infinitas possibilidades que ele nos traz.

\subsection{Diálogo}

O diálogo não é uma discussão que visa fechar questões ou convencer interlocutores ou defender ideias. Pelo contrário, visa a compreensão e a emergência de ideias novas, só possível pelo estabelecimento de novas relações que surgem na interação, na troca de ideias similares, na escuta atenta ao que é novo, no ir além do que aparentemente é antagônico.

"Num diálogo cada pessoa não tenta tornar comuns certas ideias ou fragmentos de informação por ela já sabidos. Em vez disso, pode-se dizer que os interlocutores estão fazendo algo em comum, isto é, criando juntos alguma coisa nova” (BOHM, 2005, p. 29). O diálogo visa melhorar a comunicação entre as pessoas, por meio do desenvolvimento de significados e sentidos comuns que surgem da interação. (MARIOTTI, 2005)

Mariotti (2005) destaca alguns pontos relevantes para considerarmos um diálogo com estas características. Primeiramente, a importância de sairmos do automatismo "concordo-discordo", através do qual, ao ouvirmos algo, em seguida julgamos se concordamos ou não. Neste automatismo, se concordamos, podemos suspender a escuta, porque já sabemos o que está sendo dito. Se discordamos, começamos a organizar uma intervenção, argumentando contra o que ouvimos. Em qualquer uma das situações, não damos a quem fala a possibilidade de ouvi-lo até o fim e com isso perdemos a oportunidade de aprender algo novo. Assim, quando tencionamos manter um diálogo, é preciso evitar este automatismo, suspendendo temporariamente nossas certezas, nossos pressupostos. É, inclusive, um exercício interessante, de reconhecimento dos condicionamentos de nosso pensamento, que nos permite entrar em contato com o novo. Ao dialogar, temos a chance de conhecer a lógica de raciocínio do outro. Destaca ainda Mariotti (2005) que, enquanto ouvimos, não podemos nos 'ausentar', mas podemos, na abertura ao pensamento do outro, reconhecer os sentimentos que tal pensamento causa em nós.

O silêncio também faz parte do diálogo. Para dialogar, antes de tudo é preciso aprender a ouvir, permanecer atentos às nossas reações ao que ouvimos. "É importante perceber aquilo que a fala (ou o silêncio) do outro produz em nós: impaciência? Inquietação? Desconfortos em determinadas partes do corpo? Alterações no ritmo cardíaco e na respiração? Aborrecimento? Ansiedade? O que 
mais?" (MARIOTTI, 2005, p. 5) Com isto, o diálogo assume perspectiva não só intelectual, mas global.

Dialogar é também pôr-se à prova. Sem isto, a criatividade não encontra espaço em um grupo de diálogo. Tem a ver com desapego, com a vontade de lançar-se em busca de algo novo, não conhecido ou imaginado a priori. Tem a ver com aventura e confiança no grupo que dialoga. Tem a ver com entrega e cumplicidade. Por isso não há receitas para dialogar, mas princípios, como ouvir para aprender, respeitar as diferenças e a diversidade, refletir sem julgar, ter em mente o objetivo, que é criar e aprender, e não vencer uma disputa de ideias (MARIOTTI, 2005).

No diálogo, aprendendo outras formas de pensar e compreender, podemos nos lançar e construir ações inusitadas, tendo a flexibilidade como base de novas experiências, de mudanças, de transformações.

\subsection{Flexibilidade}

Flexibilidade, segundo o dicionário Houaiss (2014), é a característica de quem é compreensível; a habilidade de contornar ou solucionar problemas ou situações difíceis; a capacidade de não se ater a modelos ou padrões rígidos de pensamento ou de comportamento; a propriedade do que é dócil ao manejo.

A flexibilidade, como princípio, nos leva a reconfigurar as propostas, buscando novas alternativas, sem nos ater a modelos ou padrões pré-formados, por melhores que tenham sido as experiências vivenciadas. Integrar o novo contexto é sempre um desafio. Consideramos, nesta compreensão, dois princípios da complexidade (MORIN, 2007): retroatividade e recursividade. A retroatividade nos diz que a causa age sobre o efeito e todo efeito retroage informacionalmente sobre a causa. A recursividade vai além do princípio retroativo, favorecendo processos de auto-organização. Produtos e efeitos são eles produtores e causadores daquilo que os produziu, rompendo com a linearidade causa-efeito, produto-produtor. Assim, devemos ser capazes de aprender com os processos, com as reviravoltas, com as mudanças, revendo e replanejando sempre que necessário, mantendo, ainda e continuamente a abertura, a escuta e o diálogo.

Compreender a flexibilidade é também viver o paradoxo de ser maleável sem perder a identidade, os princípios adotados. Até que ponto podemos "vergar" sem descaracterizar o que acreditamos, o que temos por espinha dorsal de uma proposta? Como grupo, é importante o auto-conhecimento, o reconhecimento de nossos objetivos, do que consideramos nossa missão como Programa, como extensão universitária, como formação de educadores. 
Ser flexível, mais do que adotar um princípio que nos pareça coerente, especialmente quando falamos em parcerias institucionais, unindo realidades diferentes, é ater-se a algo que faz parte da realidade. Edgar Morin (2000a) apresenta a ecologia da ação, dizendo que toda a ação, depois de lançada, escapa às intenções de quem a iniciou. Abrir-se à ecologia da ação, na medida em que é percebida, é abrir-se à realidade que comporta o inesperado, o imprevisto, as transformações, as emergências. Para acolher a ecologia da ação é preciso abrir mão de etapas programadas, determinadas a priori. Os programas são úteis em condições externas estáveis. Mas a realidade tem poucas situações estáveis, estanques, não sujeitas a mudanças e a imprevistos. Morin (2000b) então nos sugere a estratégia, que também é estabelecida a partir de um objetivo. No entanto, encontra os encaminhamentos da ação, escolhendo os que se mostrem mais adequados aos acasos e às informações colhidas ao longo do percurso. Cabe à equipe reunir as informações dispersas dos diversos interlocutores, dando corpo e sentido ao conjunto, cuidando do círculo recursivo e retroativo.

A estratégia traz em si a consciência da incerteza que vai enfrentar e, por isso mesmo, encerra uma aposta. Deve estar plenamente consciente da aposta, de modo a não cair em uma falsa certeza. Foi a falsa certeza que sempre cegou os generais, os políticos, os empresários, e os levou ao desastre. (MORIN, 2000b)

Acreditamos que, atuando com base na ecologia da ação, geramos condições para que algo novo emerja, tendo a oportunidade de vivenciar processos criativos, significativos, que façam sentido para as diferentes instituições e grupos envolvidos. Edgar Morin (2000b) fala em aposta. Reconhecemos a aposta que pode nos levar a alternativas que não seriam sequer imaginadas em procedimentos que desconsiderem a ecologia da ação, o espaço de diálogo. Maria Cândida Moraes (2008) salienta que, como educadores, fomos educados para sermos os donos da verdade, impossibilitados de errar ou de demonstrar qualquer dificuldade, ignorância ou erro a respeito do que quer que seja. "E, hoje, embalados pelas mais variadas emergências e imprevistos da vida, temos que resgatar a humildade para que ela nos ajude a reconhecer a existência de algo que não sabemos e a necessidade de se buscar outras respostas" (MORAES, 2008, p. 103).

As mudanças, os ajustes não devem, no entanto, ser decididos por uma das partes dos envolvidos no projeto. É preciso partilha, para que os parceiros sintam-se, ao longo de todo o processo, autores, comprometidos, integrados. 


\subsection{Partilha}

Partilhar uma proposta, mais que isso, partilhar um planejamento e as ações dele decorrentes nos dão algumas certezas. Certeza de que os passos serão sempre os mais adequados, passando pelo diálogo capaz de reajustar cada passo. Certeza de que não nos afastaremos da realidade local, na tentação de retomar o conhecido, reviver (como se fosse possível) o já vivido, deixando de lado os desafios dos novos contextos e da nova situação que se consubstancia.

Partilhar a operacionalização é uma maneira de buscarmos a coerência entre nossa crença de que aprendemos com o outro, e da importância, mais uma vez, dos diferentes olhares para a configuração da realidade.

Partilha nos faz pensar em participação no sentido de tomar parte, dar uma contribuição. David Bohm (2005), em seu livro Diálogo: comunicação e redes de convivência, nos apresenta o pensamento participativo, identificável nas primeiras culturas humanas. É uma forma diferente de perceber e pensar, na qual as pessoas sentiam que participavam de algumas das coisas que viam, "percebiam que tudo no mundo era participativo e que o espírito de todas as coisas era único" (BOHM, 2005, p. 150). Esta maneira de conceber nos dá a sensação de 'estar-juntos'. É esta sensação que buscamos no momento de partilha. Integrando as contribuições, num processo de construção e ajustes em conjunto, tentamos encontrar um "produto" que contemple um pouco de cada sujeito do grupo, dos parceiros, dos representantes das instituições envolvidas.

Sem dúvida o tempo de escuta, formulação, diálogo, torna o planejamento e replanejamento mais longos. Mas o inesperado, o inusitado, a inovação não são mera improvisação, são frutos das interações, da partilha e da auto-organização.

\subsection{Auto-organização}

O conceito de auto-organização nos lembra a autopoiese, de Maturana e Varela (1995), que caracteriza o ser vivo. Autopoiese é a capacidade de um ser vivo acolher a desordem natural decorrente do novo, pela inserção de um contexto diferente e/ou de interações diversas com o meio.

O mesmo conceito podemos direcionar para um grupo. Um novo projeto, a concepção de alternativas mediante uma proposta e a junção de novos parceiros podem representar um momento de desordem. Acolhida a desordem, é necessário entrar em processo de auto-organização, mediante interações dialógicas, mudando/criando para que uma nova ordem possa surgir, adequada à realidade complexa, aos objetivos, 
às demandas dos ciclos recursivos e retroativos em que estamos imersos e às emergências. $\mathrm{O}$ momento de auto-organização permite a aprendizagem com os processos vividos, com o novo, com o inesperado e com as incertezas decorrentes de projetos que não são fechados.

Estes seis princípios nos permitem, a cada nova parceria, encontrar na co-participação a aprendizagem inovadora dada pela construção conjunta dos marcos do programa,propiciando a contextualização à realidade local.

Por coerência, as ações do Programa Geração da Paz, na formação de educadores para a cidadania, devem também incluir a abertura, a escuta, o diálogo, a flexibilidade, a partilha e a auto-organização. Os princípios perpassam todos esses diferentes níveis de ação (gestão, formação, extensão).

\section{Projeto Criação da Rede de Agentes de Cidadania}

Relatamos em seguida a prática desses princípios no Projeto Criação da Rede de Agentes de Cidadania: caminhos para a vivência dos direitos humanos e geração da paz, desenvolvido, entre os anos de 2012 a 2014, no município de Horizonte, no estado do Ceará/Brasil. Tem por objetivo geral estabelecer uma rede de agentes de cidadania, propiciando a interlocução pautada nos direitos humanos como forma de favorecer uma cultura de paz no município. É uma das ações do Programa Geração da Paz. Foi composto por quatro etapas principais: (1) formação teórico-prática dos educadores para a cidadania; (2) formação metodológica transdisciplinar dos educadores; (3) criação dos materiais didáticos; (4) e realização do curso dos agentes de cidadania pelos educadores formados, entre os anos 2013 e 2014. (SCHERRE, 2013)

Os princípios, além de constarem formalmente como itens escritos no Programa, perpassam pelos distintos e interdependentes níveis - cada qual constituído por relações, ações, interações, estratégias e características próprias - representados por: (1) coordenação do projeto, (2) construções colaborativas das formadoras, (3) docência e metodologia de formação dos educadores.

Ao longo de todo o processo, a coordenação do projeto feita por um Núcleo Gestor constituído pelas formadoras e por representantes da prefeitura com suas várias secretarias, como a de educação; a de desenvolvimento e inclusão social; a de cultura; a da saúde; a do desenvolvimento econômico; a institucional e política.

O embrião deste projeto, em abril de 2012, tinha como proposta, inicialmente, fazer uma formação em direitos humanos, cidadania e geração da paz para os professores de escolas públicas do município. Mas, por movimentos de abertura, diálogo e escuta das 
necessidades locais, em conversa com a Secretaria de Educação, o projeto se expandiu, abarcando outras secretarias e buscando como foco a formação, ao final, de uma Rede de Agentes de Cidadania. Podem ser Agentes de Cidadania: os integrantes de movimentos sociais e comunitários, os agentes de saúde, os participantes dos conselhos escolares e as lideranças políticas, comunitárias, estudantis, sindicais ou religiosas.

A concepção e realização deste Projeto têm sido feitas em diálogos constantes com o Núcleo Gestor, responsável por coordenar os processos de formação e de planejamento e acompanhamento do cronograma e por viabilizar as ações junto à prefeitura, como transporte, alimentação e liberação de educadores(as) que fossem funcionários municipais. Na coordenação do projeto, a flexibilidade e a auto-organização também se fizeram presentes na adaptação contínua de cronogramas e recursos, conforme as demandas apresentadas pelos educadores e a realidade e possibilidades do município. Em um movimento cíclico, as decisões do Núcleo Gestor também eram partilhadas e dialogadas com os educadores como forma de contemplar as diferentes visões e necessidades e de permitir que todos tivessem acesso às mesmas informações.

No nível das construções colaborativas das formadoras, foram processos vivenciados em conjunto - coordenação do curso, planejamento, docência, reflexão e pesquisa - onde temos os princípios presentes e imbricados: diálogos a respeito de diferentes temáticas a todo momento compartilhadas entre as formadoras; partilha de ideias e propósitos e das decisões e ações realizadas sempre em comum acordo, mas com respeito e abertura às diferentes opiniões e visões sobre um determinado assunto; flexibilidade e auto-organização na contínua construção do Projeto, das reuniões, dos planejamentos das atividades de formação presenciais e virtuais, de acordo com as emergências que surgiram na relação com os educadores e com o Núcleo Gestor. Algumas outras características também se fizeram presentes nessas construções colaborativas, como: a confiança mútua de que decisões e ações foram feitas de forma ética e respeitosa; o carinho expresso por palavras sensíveis, sorrisos, abraços e um "ombro amigo" em momentos difíceis; a amizade presente nas trocas, para além do projeto, na qual compartilhamos momentos de vida, sonhos e criações; a transparência e a clareza das ações, por meio da comunicação, de forma que todas pudessem saber sobre as decisões a respeito do caminho que estava sendo percorrido pelo Projeto.

Nessa relação entre as formadoras, os processos de pesquisa e de questionamentos sobre a metodologia desenvolvida, bem como nossa própria formação se fizeram sempre presentes. Continuamente, por meio do diálogo e da escuta, buscamos atenção à fundamentação teórica de nossas ações e coerência entre a teoria que temos como base e a prática que empreendemos. 
No nível da docência e da metodologia de formação dos educadores, nos momentos presenciais, por exemplo, estiveram sempre presentes o diálogo e a escuta dos(as) educadores(as), explicitando a abertura das formadoras para que, a qualquer momento, eles(as) pudessem se sentir à vontade para falar, para solicitar pausa e, mesmo, para pedir uma reorganização, caso o que estivesse sendo trabalhado não fizesse sentido. Em nossas falas, explicitávamos também nossa abertura às emergências e à necessidade de replanejar, de se auto-organizar e de flexibilizar o que havia sido planejado para atendê-las. Houve também partilhas com os(as) participantes sobre reorganizações do planejamento. Ao serem informados(as) sobre as alterações, eles(as) podiam fazer propostas e/ou se expressar sobre as modificações sugeridas.

As atividades pedagógicas envolveram diferentes sentidos (audição, visão, olfato, paladar, tato), diferentes dimensões do ser humano (cognitiva, expressiva, física, emocional, intuitiva, espiritual, social, individual, coletiva, política, biológica), habilidades (leitura, escuta, diálogo, fala, reflexão, sistematização, expressão em diferentes linguagens - música, desenho, poesia, dissertação) e conhecimentos (integração dos saberes prévios pessoais e profissionais de cada um, com as leituras realizadas individual ou coletivamente, e com os saberes das tradições).

Estas atividades foram organizadas de modo a harmonizar atividades que desenvolvessem diferentes dimensões, habilidades e conhecimentos dos(as) participantes ao longo de cada período de formação. Houve também o cuidado com a retomada das atividades de um dia para o outro e dentro de um mesmo módulo, buscando uma linha de trabalho e continuidade dos processos vivenciados e permitindo o avanço e o aprofundamento das reflexões e diálogos realizados.

Foram frequentes também momentos de diálogo entre as formadoras, antes, durante e depois de cada encontro presencial ou de cada atividade virtual, para planejamento e replanejamentos necessários, compondo o caráter auto-organizativo e flexível da nossa ação conjunta.

Por meio de depoimentos espontâneos dos(as) educadores(as) (SCHERRE; ARNT, 2014), podemos ter uma noção do quanto esses princípios, presentes no curso e na metodologia de formação, abriram espaços para que eles(as) desenvolvessem a escuta atenta e a flexibilidade de ações e decisões.

O Educador M., que trabalha na área da cultura, desenvolveu o parar para escutar ao meio:

Educador M: [...] o aprender a ouvir e escutar. Uma experiência pessoal mesmo... há muito tempo eu não escutava, eu não parava pra ouvir coisas 
simples. Aquela experiência de ouvir... vamos parar pra escutar... de vez em quando eu me pego lá em casa... vou parar e vou ouvir. Eu aprendi isso e estou levando pra minha vida. [...]

A Educadora I., que atua na área de comércio, desenvolveu a escuta atenta do meio e dos outros:

Educadora I.: [...] E também o escutar... [...] quando a gente fechou o olho e parou pra escutar, a gente começou a ouvir coisas que a gente não ouvia antes. [...] é muito bom a gente parar pra escutar o que o outro tem pra nos dizer. Às vezes a gente nem para pra ouvir, só fala.

A Educadora P., que trabalha com grupo de jovens em situação de risco, destaca a importância da escuta atenta também no contexto familiar.

Educadora P.: [...] porque eu acho que a gente deve partir do princípio de que ele (o curso) não leva frutos somente para o nosso ambiente de trabalho, ele também leva frutos para a nossa própria família. [...] porque às vezes você não tem esse momento de escuta [...] dentro da sua própria casa. Esses momentos (do curso) fazem que a gente reflita, para que a gente possa ter esse momento de escuta dentro da nossa própria família.

A Educadora F., que atua na ouvidoria do município, relata a importância da escuta atenta do outro e da abertura para a reflexão e diálogo que esta escuta possibilita. Além disso, comenta da importância da flexibilidade do planejamento para que as necessidades e momento do outro sejam considerados.

Educadora F.: [...] Primeira coisa é aprender a ouvir, porque, às vezes, você não deixa o outro falar. [...] Ouvir é tudo de bom, porque [...] você vai dar a oportunidade [...] quando ele está relatando tudo aquilo, automaticamente, ele está refletindo também. [...] A gente tem que se habituar a isso, não fechar a coisa e punir e dizer que é assim... porque não tem nada pronto. Eu vi aqui... eu vejo isso aqui. Eu estou aprendendo aqui com vocês, não tem nada pronto. Você está aqui. Você monta um método todinho, está tudo aqui no roteiro. De repente, esse roteiro foi para o espaço. Mudou tudo. Você se vê na possibilidade de mudar... [...] Eu acho isso muito bom. A gente evolui, enriquece, melhora enquanto ser humano, e contribui, quando você vê que passou aquela coisa mínima... Ás vezes aos seus olhos não é tão importante, mas [...] para o outro, foi uma grandiosidade. É muito legal, isso aqui é uma riqueza... 
O Educador E., que é coordenador em uma escola pública, também comenta da sua mudança de atitude e de compreensão, ao se dar tempo para escuta atenta do outro e a abertura de espaço para diálogo e reflexão sobre o ocorrido.

Educador E.: Já influenciado por este curso, pelo que a gente passa aqui. [...] na coordenação da escola que eu estou, às vezes, a gente tinha só a ação. $\mathrm{O}$ aluno vinha e fazia aquilo lá que não era pedagógico para a escola e ele já saia de lá com uma suspensão, uma chamada para os pais. E na correria, não dava tempo de sentar, analisar a situação, fazer todo um percurso para depois [...] você ir para a ação. E ultimamente eu tenho feito isso... tento parar, sentar para escutar mais e... [...] tento manter a calma e digo: o que é que aconteceu, relate tudo? [...] Aí depois ele começa a refletir... (o aluno pergunta) você não vai me dar suspensão? Eu digo: você merece? Ele diz: Não, eu acho que não... Aí eu vejo que começa a ter uma reflexão em cima da ação dele. Não é mais aquela coisa seca de ir para uma coordenação e já sair dali com algo punitivo pra ele. É o que é o que ele compreende e também é o que a gente fazia na correria do dia a dia. Então, assim, eu acho que realmente o curso tá, direta e indiretamente, já interferindo na nossa prática mesmo cotidiana dos nossos fazeres.

Além da consciência que temos a respeito desses princípios e da busca pela coerência e vivência deles em nossas ações de coordenação, de construção conjunta e de docência, compreendemos que estes princípios repercutem em transformações do ser e também nos mais diferentes contextos nos quais essas pessoas vivem e convivem, ao estarem mais atentos a si e ao outro, mais abertos à escuta e ao diálogo e à flexibilidade em suas ações cotidianas.

\section{Considerações finais}

O Programa Geração da Paz tem outros projetos em andamento. Em todos, os princípios são referência das ações e das parcerias firmadas. Temos observado a receptividade de propostas abertas e a participação comprometida gerada pelo diálogo, construção conjunta, partilha. Constantemente as ações educativas têm sido alvo de críticas pelo desinteresse dos alunos, pela apatia e tédio em sala de aula. É como se a escola já não suscitasse questionamentos nos alunos, como se trabalhasse com respostas prontas a perguntas que ninguém fez.

Pensamos em um perfil profissional para o professor do futuro, acreditamos 
que mais do que pensar no futuro, há a necessidade de nós, professores, nos repensarmos agora, refletindo sobre nossas ações docentes e sobre os princípios que as organizam. Compreendemos princípios como pontos de partida sobre os quais construímos a docência. Os princípios aqui apresentados (abertura, escuta, diálogo, flexibilidade, partilha, auto-organização) não são únicos nem estanques, representam a sistematização que fizemos até agora. Outros professores e profissionais podem ter e sistematizar outros princípios. Uma questão importante é que cada um(a) esteja atento(a) aos seus princípios, revisando-os, buscando coerência entre eles e suas práticas. Esperamos que os nossos princípios sirvam de inspiração para que outros docentes também façam esse exercício de tomar consciência e, assim, caminhar em sua (auto)formação inicial e continuada.

Finalmente, pensamos em nossas pesquisas sobre processos de formação docente e na pergunta proposta: qual é o perfil profissional, que competências, conhecimentos e habilidades deverá ter, e como se poderia formar o professor do futuro?

Consideramos que ao longo das últimas décadas muito avançamos sobre a didática disciplinar e mesmo sobre a maneira de integrar disciplinas. Mas é na simplicidade de manter-se aberto, escutar o outro em profundidade, atenta e sensivelmente, dialogar como quem quer compreender o nível de realidade do interlocutor, sua maneira de ser, de pensar, de entender o mundo. Encontrar caminhos de compreensão... talvez um bom começo.

\section{Referências}

ARNT, R. M. Docência transdisciplinar: em busca de novos princípios para ressignificar a prática educacional. São Paulo: Programa de Pós-graduação em Educação: Currículo, PUC/SP. Tese de doutorado, 2007. Disponível em: $<$ http://www.sapientia.pucsp. br/tde_busca/arquivo.php?codArquivo=4742>. Acesso em: 30.out. 2015.

BARBIER, R. A pesquisa-ação. Brasília: Plano, 2002.

BOHM, D. Diálogo: comunicação e redes de convivência. São Paulo, Palas Athena, 2005.

FREIRE, P. Pedagogia da Autonomia. São Paulo: Paz e Terra, 1997. 
HOUAISS, A. Dicionário Houaiss da Lingua Portuguesa. Disponível em <http:// houaiss.uol.com.br/busca?palavra=flexibilidade>. Acesso em: jul.2014.

MARIOTTI, H. Diálogo: um método de reflexão conjunta e observação compartilhada da experiência. Disponível em: <http://www.geocities.com/ pluriversu/dialogo. html>. Acesso em: 30.out. 2015.

MATURANA, H.; VARELA, F. A árvore do conhecimento. Campinas: Psy II, 1995.

MORAES, M. C. Ecologia dos saberes, Complexidade, Transdisciplinaridade e educação: novos fundamentos para iluminar novas práticas educacionais. São Paulo: Antakarana/WHN - Willis Harman House, 2008.

MORIN, E. Introdução ao Pensamento complexo. Tradução de Eliane Lisboa. 3 ed. Porto Alegre: Sulina, 2007.

MORIN, E. Os sete saberes necessários à educação do futuro. São Paulo: Cortez, 2000a.

MORIN, E. A Cabeça bem feita: repensar a reforma, reformar o pensamento. Rio de Janeiro: Bertrand Brasil, 2000b.

SCHERRE, P. P. Curso de formação dos educadores para a cidadania: tecendo uma metodologia transdisciplinar, 2013. In: Anais do XI Congresso Nacional de Educação Educere. Pontificia Universidade Católica do Paraná. Disponível em: <http://educere. bruc.com.br/ANAIS2013/pdf/7709_5694.pdf>. Acesso em: 30.out. 2015.

SCHERRE, P. P.; ARNT, Rosamaria de Medeiros. Aprender a ser: repercussões da metodologia transdisciplinar na formação de educadores. In: Anais do VI Forum Internacional de Innovación y Creatividad: Escuelas y aulas creativas. Universidade de Barcelona, 2014.

Recebido em: 14 março 2016.

Aceito em: 29 de março 2016. 